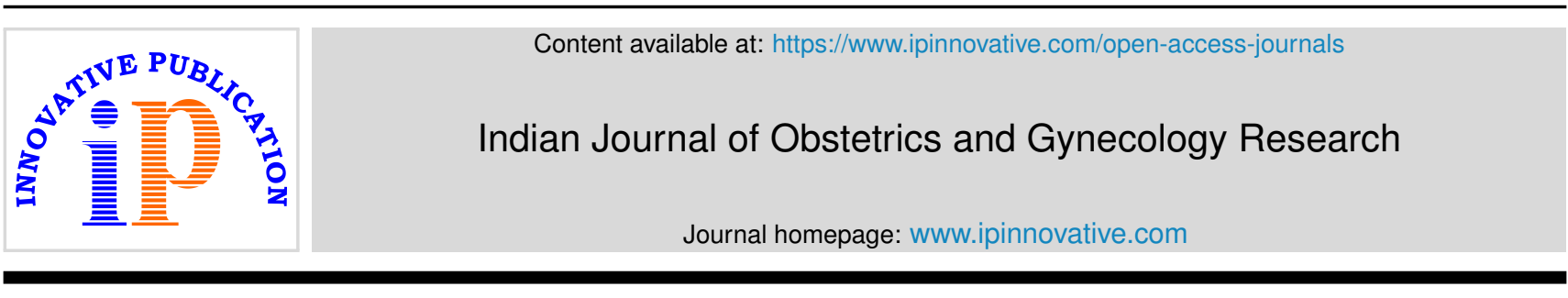

Original Research Article

\title{
A clinical study on the utility of alert and action line on partogram in management of labor in primigravidae and its impact
}

\author{
Deepika Verma $^{1}$, Surabhi Gupta ${ }^{1, *}$ \\ ${ }^{1}$ Dept. of Obstetrics and Gynecology, Index Medical College Hospital and Research Center, Indore, Madhya Pradesh, India
}

\section{A R T I C L E I N F O}

\section{Article history:}

Received 30-03-2020

Accepted 18-04-2020

Available online 12-09-2020

Keywords:

Primigravida

Partogram

Alert line

Action line

Modified WHO partogram

Labor

\begin{abstract}
A B S T R A C T
Background: A good maternal and fetal outcome is of utmost importance for any obstetrician and 'partogram' is a very simple and important tool for such assessment.

Objective: To analyse the patterns of labor amongst spontaneous parturient using a WHO modified partogram and to compare outcome of labor and neonatal outcomes in relation to partogram findings.

Materials and Methods: This prospective study was carried over a period of 18 months on 100 parturients. Modified WHO Partogram was used to assess the progress of the labor. Parturients were divided on basis of partogram findings. Group-I $(\mathrm{n}=64)$, where parturients partogram remained to the left of alert line, GroupII $(n=20)$, where parturients partogram remained between the alert and action lines and Group-III $(n=16)$, where parturients partogram crossed the action line. In these three groups, the maternal and fetal outcomes were assessed.

Results: Normal vaginal delivery was done in $95.3 \%$ of Group-I, $80 \%$ of Group-II and $43.75 \%$ of Group-III parturients. Instrumental delivery was done in $1.56 \%$ of Group-I, $10 \%$ of Group-II and $18.75 \%$ of GroupIII parturients. LSCS was done in $3.1 \%$ of Group-I, $10 \%$ of Group-II and 37.5\% of Group-III parturients. Instrumental / LSCS deliveries were higher in Group-II and Group-III parturients. A large proportion of newborns of Group-II and Group-III parturients had Apgar Score $<7$.

Conclusions: The Modified WHO partogram is very helpful in the prediction of maternal and fetal outcome. It is highly recommended for use in resource deficient medical facilities, where early decision for delivery or referral can be taken on the basis of partogram findings.
\end{abstract}

(C) 2020 Published by Innovative Publication. This is an open access article under the CC BY-NC license (https://creativecommons.org/licenses/by-nc/4.0/)

\section{Introduction}

The journey through birth canal is considered the most dangerous of all the journeys a human takes throughout their life,,$^{1,2}$ and hence it becomes most important for the obstetrician and gynaecologist to see that this journey is made safe both for the baby and the mother. Labor is a natural physiological process, which is characterized by progressive increase in frequency, intensity and duration of uterine contractions, resulting in effacement and dilatation of cervix, with descent of the fetus through the birth canal. Many a times, this physiological process is extended, leading to prolonged labor.

\footnotetext{
* Corresponding author.

E-mail address: surabhigupta391@gmail.com (S. Gupta).
}

Extended labor is associated with significant adverse maternal and fetal outcomes. It can lead to maternal fatigue, maternal sepsis, obstructed labour, uterine rupture, postpartum haemorrhage, perinatal asphyxia, neonatal sepsis, impairment which can lead to stillbirth, neonatal death and even maternal death. ${ }^{2-5}$ Hence the common axiom is "Never let the sun set twice on same labor". 6

'Partogram' or partograph is a combined graphical archive of vital data for both mother and fetus during childbirth viz. cervical dilatation, fetal heart rate, duration of labor and vital signs, which is entered against the time on the same sheet of paper. ${ }^{7}$

It was Dr. Friedman who, in 1954, plotted the labor of a woman on a graph and demarcated that all regular labor had a typical sigmoid-shaped curve and also identified various 
stages of labor and irregular patterns of labor. ${ }^{2,8}$ In 1972, Philpott invented a composite work picture and added the alert and action lines to the partogram. ${ }^{2,9}$ In 1994, World Health Organization (WHO) endorsed the Partogram and later in the year 2000, it was modified. The latent phase was removed and the active phase was placed at $4 \mathrm{~cm}$, instead of its earlier position at $3 \mathrm{~cm}$. Then $\mathrm{WHO}$ advocated and recommended its universal use during labor for labor management. ${ }^{2,10}$

Till date, the partograph developed by the World Health Organization is considered the best. It simplifies the clinical interpretation of the dynamic changes that occur during labor. Any deviation from the normal curve, alarms for the possibility of a labor disorder in advance. It helps not only in recognition but also in characterization and management of dysfunctional labor. Being a very simple and useful tool, helpful in making early decision regarding delivery at the periphery or referral of the parturient to the higher center, when the progress of the labor is found to be abnormal. ${ }^{11}$ Thus, helping in reduction of maternal and fetal morbidity. ${ }^{11,12}$

Based on uterine contractions, cervical dilatation and cervical effacement, the progress of labor can be easily assessed. Once the labor onsets, there is possibility of regulating the duration and progress with complete success, which requires a systematic approach with careful diagnosis of onset of labor, regular assessment and decision making.

Considering the various benefits that partogram could provide during labor, the present study was designed to evaluate early detection of abnormal labor progress using partogram, prevention of prolonged labor, early decision on increase or termination of labor with early recognition of maternal and fetal problems, and assessment and management of various complications due to prolonged labor; and assessment of maternal and fetal outcome based on the partogram findings.

\section{Aims and Objectives}

1. Early detection of abnormal progress of labor.

2. Prevention of prolonged labor.

3. Assist in early decision on augmentation or termination of labor.

4. Early recognition of maternal and fetal problems.

5. Reducing complications due to prolonged labor in mother like PPH, sepsis, uterine rupture and its sequele and in new born like death, hypoxia, infection etc.

\section{Material and Methods}

The present prospective observational study was conducted in the Department of Obstetrics \& Gynecology, Index Medical College Hospital \& Research Center, Indore (M.P.) during the study period January 2018 to June 2019 on 100 primigravidas of $37-40$ weeks gestation with singleton pregnancy, meeting all the inclusion criteria and none of the exclusion criteria. The study protocol was submitted to the Ethics Committee of Index Medical College Hospital, Indore (M.P.) and the study was initiated at the institution after their approval.

\subsection{Inclusion criteria}

1. Primigravida, aged 19-34 years, who had 37- 40 weeks gestation

2. Single live fetus in vertex presentation.

3. Woman irrespective of induced or spontaneous onset of labor.

4. Parturient in active phase of labor $(4 \mathrm{~cm}$ or more of cervical dilatation).

5. Parturient and/or her legally acceptable representative willing to provide their voluntary written informed consent for participation in the study.

\subsection{Exclusion criteria}

1. Multigravida.

2. Teenage pregnancy, Elderly primigravida

3. Multiple pregnancies..

4. Malpresentation.

5. Post term Pregnancy, Preterm labor.

6. Severe oligohydramnios, Polyhydramnios.

7. Contracted pelvi.

8. Cephalopelvic Disproportion.

9. Medical comorbidities i.e. PIH, Diabetes mellitus, heart disease, epilepsy.

10. Parturient and/or her legally acceptable representative not willing to provide their voluntary written informed consent for participation in the study.

\subsection{Methodology}

The parturient and her legally acceptable representative were explained in detail about the study, its benefits/risks, procedures, compliance from the parturient side, etc. And after obtaining their verbal consent for participation, a voluntary written informed consent was obtained. All the study related procedures were initiated after obtaining voluntary written informed consent.

After admission in the labor room, a detailed history regarding age, last menstrual period, expected date of delivery, duration of pregnancy, menstrual history, marital life, chief presenting complains viz. leaking and bleeding per vaginum, show and labor pains was noted. A thorough examination was conducted according to the parameters mentioned in the customized proforma. She also underwent general physical. Cardiovascular and respiratory system examinations were also done to rule out any systemic disease.

Per abdominal examination was done according to Leopold's maneuver. Height of uterus (symphysio-fundal 
height), abdominal circumference and amount of liquor was noted. The presentation, lie of fetus and position of the fetus was confirmed. Crichton rule of fifth was used to note the part of head palpable per abdomen in fifths.

The duration, its intensity and uterine contraction frequency (per 10 minutes) were noted. Pelvic examination was done for pelvic assessment and Bishop Score calculation was also done. The course of labor of each parturient was recorded on modified WHO partograph after the onset of labor.

\subsection{Customized proforma was designed for the present study, where all the data was captured}

Based on the partogram findings, the parturients were divided into three groups:

Group I ( $n=64)$ : Parturients who delivered on or before the alert line in the partogram

Group II $(n=20)$ : Parturients who delivered between the alert line and action line in the partogram

Group III $(n=16)$ : Parturients who delivered after crossing the action line on partogram.

All these parturients were followed up till delivery.

Duration of hospital stay, mode of delivery, acceleration of labor, rate of cervical dilatation, duration of active phase, abnormal labor patterns, indication for instrumental and lower segment cesarean section, apgar score and any other maternal and fetal complications formed the outcome measures.

\subsection{Statistical analysis}

The data was captured in the customized proforma. Microsoft Excel was used for analysis of the data and online statistical software viz. GraphPad, Epi Tools, etc. were used for calculating the $\mathrm{p}$ values. Descriptive statistics was presented in the form of numbers and percentages, comparison of mean rate of cervical dilatation and comparison of mean duration of active labor was done using One-Way ANOVA, association between groups and the mode of delivery; association between indication for instrumental / LSCS delivery and association between Apgar score and the groups was done using Pearson Chisquare test. A p value of $<0.05$ was taken as statistically significant.

All the parturients made payment for their delivery and other hospital expenses according to the cost laid down by the institution. None of the parturients and / or her legally acceptable representative bore any costs related to their participation in the present study. All study related costs were borne by the investigator. Also the present study was not funded by any pharmaceutical company or any institution.

\section{Results}

Table 1: Distribution of parturients according to age group

\begin{tabular}{lcc}
\hline Age & No. of cases & Percentage $(\%)$ \\
$20-24$ years & 56 & 56 \\
$25-29$ years & 32 & 32 \\
$30-34$ years & 12 & 12 \\
Total & 100 & 100 \\
\hline
\end{tabular}

Of the 100 parturients, $56 \%$ were in the age group 20-24 years, $32 \%$ were in the age group 25-29 years and $12 \%$ were in the age group 30-34 years, with a mean age of $24.08 \pm$ 4.12 years.

Table 2: Distribution of parturients according to their partographic group

\begin{tabular}{lcc}
\hline Groups & No. of cases & Percentage $(\boldsymbol{\%})$ \\
Group I & 64 & 64 \\
Group II & 20 & 20 \\
Group III & 16 & 16 \\
Total & 100 & 100 \\
\hline
\end{tabular}

$64 \%$ parturients were in Group I, 20\% were in Group II and $16 \%$ were in Group III. Of the 100 parturients, $36 \%$ of the parturients had abnormal cervimetric progress.

In Group I 75\% parturients required acceleration of labor, in Group II 70\% parturients required acceleration of labor and in Group III all the parturients required acceleration of labor. Overall, $78 \%$ parturients required acceleration of labor.

The mean cervical dilatation in Group I was $1.4 \pm 0.023$ $\mathrm{cm} /$ hour, in Group II it was $0.7 \pm 0.03 \mathrm{~cm} /$ hour and in Group III it was $0.53 \pm 0.01 \mathrm{~cm} /$ hour. The rate of cervical dilatation was highest in Group I and slowest in Group III. The comparison of mean cervical dilation was found to be statistically significant $(\mathrm{p}=0.042)$.

Group III parturients had higher incidence of protracted / arrest of labor.

The mean duration of active phase of labor in Group I was $4.3 \pm 0.32$ hours, in Group II it was $7.77 \pm 1.23$ hours and in Group III it was $11.37 \pm 2.56$ hours. The comparison of mean duration of active phase of labor among the three groups was found to be statistically significant $(\mathrm{p}=0.001)$, with a longest duration in Group III and smallest duration in Group I.

Normal vaginal delivery was done in $95.3 \%$ parturients of Group I, $80 \%$ parturients of Group II and $43.75 \%$ parturients of Group III. Instrumental delivery was done in $1.56 \%$ parturients of Group I, $10.0 \%$ of Group II and $18.75 \%$ of Group III parturients. LSCS was done in $3.1 \%$ parturients of Group I, $10 \%$ of Group II and $37.5 \%$ parturients of Group III. There was a statistically significant association seen between groups and the mode of delivery $(\mathrm{p}=0.001)$, showing that majority of the parturients $(95.3 \%)$ 
Table 3: Distribution ofparturients according to need of acceleration of labor

\begin{tabular}{|c|c|c|c|c|c|c|c|}
\hline \multirow{2}{*}{$\begin{array}{l}\text { Acceleration } \\
\text { of Labor }\end{array}$} & \multicolumn{2}{|c|}{ Group I } & \multicolumn{2}{|c|}{ Group II } & \multicolumn{2}{|c|}{ Group III } & \multirow{2}{*}{ Total } \\
\hline & No. & $\%$ & No. & $\%$ & No. & $\%$ & \\
\hline Yes & 48 & 75.00 & 14 & 70.00 & 16 & 100.00 & 78 \\
\hline No & 16 & 25.00 & 6 & 30.00 & 0 & 0.00 & 22 \\
\hline Total & 64 & 100 & 20 & 100 & 16 & 100 & 100 \\
\hline
\end{tabular}

Table 4: Comparison of rate of cervical dilatation amongst the groups

\begin{tabular}{llcccc}
\hline Group & $\mathbf{N}$ & Mean Rate \pm SD $(\mathbf{c m} / \mathbf{h r})$ & Min & Max & P value \\
I & 64 & $1.4 \pm 0.023$ & 1 & 2 & $0.042 *$ \\
II & 20 & $0.7 \pm 0.03$ & 0.63 & 0.85 & 0.6 \\
III & 16 & $0.53 \pm 0.01$ & 0.5 & \\
\hline
\end{tabular}

Table 5: Comparison of mean duration of active phase amongst the groups

\begin{tabular}{lccccc}
\hline Group & $\mathbf{N}$ & $\begin{array}{c}\text { Duration of Active phase Mean } \pm \text { SD } \\
\text { (hours) }\end{array}$ & Min & Max & P value \\
I & 64 & $4.3 \pm 0.32$ & 3 & 6 & $0.001 *$ \\
II & 20 & $7.77 \pm 1.23$ & 7 & 9.5 & 12 \\
III & 16 & $11.37 \pm 2.56$ & 10 & & \\
\hline
\end{tabular}

Table 6: Distribution ofparturients according to mode of delivery $(n=100)$

\begin{tabular}{|c|c|c|c|c|c|c|c|c|}
\hline \multirow{3}{*}{ Groups } & \multicolumn{6}{|c|}{ Mode of delivery } & \multirow{3}{*}{ Total } & \multirow{3}{*}{$\begin{array}{c}\text { Chi } \\
\text { Square/ } \mathbf{P} \\
\text { value }\end{array}$} \\
\hline & \multicolumn{2}{|c|}{ NVD } & \multicolumn{2}{|c|}{ Instrumental } & \multicolumn{2}{|c|}{ LSCS } & & \\
\hline & No of cases & $\%$ & No of cases & $\%$ & No of cases & $\%$ & & \\
\hline I & 61 & 95.3 & 1 & 1.56 & 2 & 3.1 & 64 & \\
\hline II & 16 & 80 & 2 & 10 & 2 & 10 & 20 & $98.325 /$ \\
\hline III & 7 & 43.75 & 3 & 18.75 & 6 & 37.5 & 16 & $\mathrm{p}=0.001 *$ \\
\hline Total & 84 & & 6 & & 10 & & 100 & \\
\hline
\end{tabular}

of Group I underwent normal vaginal delivery, while a higher incidence of instrumental and LSCS deliveries was seen in parturients falling under Group II and Group III.

Of the 36 parturients of Group II and Group III, 16.7\% underwent normal vaginal delivery due to protracted descent and $47.22 \%$ underwent due to protracted dilatation. $5.55 \%$ underwent instrumental delivery due to arrest of descent and $8.33 \%$ due to protracted descent. $2.77 \%$ parturient each underwent LSCS due to failure of descent, arrest of descent and arrest of dilatation respectively, $5.55 \%$ due to protracted descent and $8.33 \%$ due to protracted dilatation.

Of the 100 parturients, 16 parturients underwent instrumental / LSCS deliveries. In Group I, all the parturients underwent instrumental / LSCS delivery due to fetal distress. In Group II, the cause of instrumental / LSCS delivery were fetal distress, arrest of descent, protracted descent and protracted dilatation accounting for $25 \%$ each. In Group III, fetal distress (22.2\%), arrest of descent $(22.2 \%)$, protracted descent $(22.2 \%)$ and $11.1 \%$ each of failure to descent, arrest of dilatation and protracted dilatation accounted for instrumental / LSCS deliveries.

Apgar score of $>7$ was seen in $98.4 \%$ newborns of Group I, $85 \%$ of Group II and $62.5 \%$ of Group III. $15 \%$ of Group II and $37.5 \%$ of Group III newborns had an apgar score $<7$.
The association between apgar score and groups was found to be statistically significant $(\mathrm{p}=0.002)$.

1 parturient of Group I had urinary tract infection (UTI). In Group II, 2 parturients each had fever and wound infection and 1 parturient had UTI. In Group III, 2 parturients each had fever, wound infection and UTI. There was no maternal mortality.

The mean duration of hospital stay in Group I was $3.42 \pm$ 0.71 days, in Group II it was $4.65 \pm 2.76$ days and in Group III it was $5.75 \pm 3.32$ days. The duration of hospital stay in Group II and III was higher than that of Group I, which was due to various complications.

\section{Discussion}

Labor during pregnancy is most simple natural physiological process, which may become dangerous for any parturient if not monitored properly. Partogram is a very simple, cost effective way to monitor the labor progress and helps in early recognition of deviation, thereby early intervention, thus improving the outcome. Present study was carried out to assess the maternal and fetal outcome based on the partogram findings. 
Table 7: Distribution of various abnormalpartographic pattern in relation to mode of delivery ( $\mathrm{n}=36$ Group II and Group III)

\section{Abnormal labor} patterns

Indications

Failure of descent

Arrest of descent

Protracted descent

Arrest of dilatation

Protracted

dilatation

Total
NVD

$\begin{array}{cc}\text { No. } & \% \\ 0 & 0 \\ 0 & 0 \\ 6 & 16.66 \\ 0 & 0 \\ 17 & 47.22\end{array}$

23

\section{Mode of delivery}

Instrumental

\section{No.}

0

2

3

0

0

5

$\%$
0
5.55
8.33
0
0

0
LSCS

$\begin{array}{cc}\text { No. } & \text { \% } \\ 1 & 2.77 \\ 1 & 2.77 \\ 2 & 5.55 \\ 1 & 2.77 \\ 3 & 8.33\end{array}$

8
Total

$\begin{array}{cc}\text { No. } & \text { \% } \\ 1 & 2.77 \\ 3 & 8.33 \\ 11 & 30.55 \\ 1 & 2.77 \\ 20 & 55.55\end{array}$

36

Table 8: Indication for Instrumental delivery and LSCS according topartographic pattern $(\mathrm{n}=16)$

\begin{tabular}{lcccc}
\hline Indication & Group I (\%) & Group II (\%) & Group III (\%) & Total (\%) \\
Fetal distress & $3(100)$ & $1(25)$ & $2(22.2)$ & $6(37.5)$ \\
Failure of descent & $0(0)$ & $0(0)$ & $1(11.1)$ & $1(6.25)$ \\
Arrest of descent & $0(0)$ & $1(25)$ & $2(22.2)$ & $3(18.5)$ \\
Protracted descent & $0(0)$ & $1(25)$ & $2(22.2)$ & $3(18.5)$ \\
Arrest of dilatation & $0(0)$ & $0(0)$ & $1(11.1)$ & $1(6.25)$ \\
Protracted dilatation & $0(0)$ & $4(100)$ & $9(100)$ & $2(12.5)$ \\
Total & $3(100)$ & & $67.234 / 0.034$ & $16(100)$ \\
Chi square/ P value & & &
\end{tabular}

Table 9: APGAR score in 1 minute

\begin{tabular}{|c|c|c|c|c|c|c|c|c|}
\hline \multirow{2}{*}{ Score } & \multicolumn{2}{|c|}{ Group I } & \multicolumn{2}{|c|}{ Group II } & \multicolumn{2}{|c|}{ Group III } & \multirow{2}{*}{ Total } & \multirow{2}{*}{$\begin{array}{c}\text { Chi } \\
\text { square/ P }\end{array}$} \\
\hline & No. & $\%$ & No. & $\%$ & No. & $\%$ & & \\
\hline $0-3$ & 0 & 0 & 1 & 5 & 1 & 6.25 & 2 & value \\
\hline 4 to 6 & 1 & 1.6 & 4 & 10 & 5 & 31.25 & 10 & $86.912 /$ \\
\hline$\geq 7$ & 63 & 98.4 & 15 & 85 & 10 & 62.5 & 88 & $\mathrm{p}=0.002 *$ \\
\hline Total & 64 & & 20 & & 16 & & 100 & \\
\hline
\end{tabular}

Table 10: Distribution according to maternal morbidity in various groups

\begin{tabular}{lccc}
\hline Indication & Group I (No.) & Group II (No.) & Group III (No.) \\
Fever & 0 & 2 & 2 \\
Wound infection & 0 & 2 & 2 \\
Fistula & 0 & 0 & 0 \\
UTI & 1 & 1 & 2 \\
Perineal Tear & 0 & 0 & 0 \\
\hline
\end{tabular}

Table 11: Duration of hospital stay

\begin{tabular}{lccc}
\hline Duration of Hospital Stay & I (No.) & Groups & II (No.) \\
3 to 5 days & 63 & 16 & III (No.) \\
6 to 9 days & 1 & 2 & 3 \\
$\geq 10$ days & 0 & 2 & 3 \\
Mean \pm SD (days) & $3.42 \pm 0.71$ & $4.65 \pm 2.76$ & $5.75 \pm 3.32$ \\
\hline
\end{tabular}




\subsection{Demographic data}

Majority of the parturients (56\%) in our study are in the age group 20-24 years, followed by $25-29$ years (32\%) and only $12 \%$ were in the age group $30-34$ years. The mean age is $24.08 \pm 4.12$ years.

\subsection{Partogram findings}

Based on the partogram findings, 64 parturients fell in Group I, 20 in Group II and 16 in Group III. Comparison based on partogram findings is shown in the (Table 12).

Studies done Philpott et al, ${ }^{9}$ Lakshmidevi et al., ${ }^{11}$ Sanyal et $\mathrm{al}^{13}$ Penumadu et ${ }^{12}{ }^{2}$ also had majority of their parturients in Group I, followed by Group II and then Group III, while study done by Bhuyar et al. ${ }^{14}$ showed majority of their parturients in Group II, followed by Group I and then Group III.

\subsection{Need of acceleration of labor}

Acceleration of labor was required in $75 \%$ parturients of Group I, 70\% of Group II and 100\% of Group III parturients in our study. Lakshmidevi et al ${ }^{11}$ also reported that $96.3 \%$ of their Group III parturients required acceleration of labor, which was supported by the study done by Bhuyar et al ${ }^{14}$ who also reported requirement of acceleration of labor more in Group III.

\subsection{Cervical dilatation}

The highest rate of cervical dilatation $(1.4 \pm 0.02 \mathrm{~cm} / \mathrm{hour})$ was seen in Group I and slowest $(0.53 \pm 0.01 \mathrm{~cm} / \mathrm{hour})$ was seen in Group III parturients. In Group III, slow rate of cervical dilatation was the main cause for the shift of curve towards right, giving rise to protracted / arrest of labor, thereby leading to increased duration of active phase of labor. Thus, delaying the progress of labor. The comparison of mean cervical dilatation was found to be statistically significant $(\mathrm{p}=0.042)$. Comparison of mean cervical dilatation in relation to partogram findings with other authors is given in Table 13.

Our results are in corroboration with the studies done by Lakshmidevi et al ${ }^{11}$ and Bhuyar et al, ${ }^{14}$ while the studies done by Philpott et $\mathrm{al}^{\mathbf{9}}$ and Garg et al ${ }^{15}$ showed a higher cervical dilatation in Group I and II and very slow cervical dilatation in Group III.

\subsection{Mean duration of active phase}

The mean duration of active phase was highest in Group III (11.37 \pm 2.56 hours), followed by Group II (7.77 \pm 1.23 hours) and lowest in Group I (4.3 \pm 0.32 hours). Comparison among the groups was found to be statistically significant $(\mathrm{p}=0.001)$. The mean duration of active labor increased from normal to abnormal labor patterns. Higher morbidity was seen in parturients with longer duration of active phase of labor.

The mean duration of active phase of labor in Group I in our study was comparable with the studies done by Lakshmidevi et al ${ }^{11}$ and Bhuyar et al, ${ }^{14}$ while the mean duration of active labor was higher in our study in both Group II and Group III parturients in comparison to these studies.

\subsection{Mode of delivery}

The incidence of instrumental / LSCS deliveries increased from Group I to Group III parturients in our study, while incidence of normal vaginal delivery increased from Group III to Group I parturients. Although parturients in Group II required intensive monitoring and active management of labor, the likelihood of FTND is still high.

Studies done by Philpott et al, ${ }^{9}$ Lakshmidevi et al ${ }^{11}$ and Penumadu et $\mathrm{al}^{2}$ reported a higher incidence of LSCS in parturients of Group III and Group II in comparison to the Group I parturients. In our study, we still had a higher incidence of normal vaginal delivery in comparison to instrumental and LSCS deliveries in Group III parturients.

Different studies are showing different rate of outcome of labor (NVD, instrumental and LSCS) in three groups, which do not seem to be totally comparable with one another. This could be due to individualized decision taken by obstetrician as shown in Table 15.

All the authors found that as the labor curve move towards right of the alert line, there is increase in operative interferences and these interferences are significantly increased once the labor curve crosses the action line.

With extensive monitoring of mother and fetus the slow cervimetric progress can be allowed to cross action line and vaginal delivery (normal and instrumental) can be taken provided the consent for continued trial is obtained as shown in Table 15.

\subsection{Abnormal labor patterns (Group II And III, $n=36$ )}

Of the 36 parturients, protracted dilatation accounting for $55.5 \%$ parturients was the most common abnormal labor pattern, followed by protracted descent seen in $30.5 \%$ parturients and then $8.3 \%$ parturients with arrest of descent. $47.22 \%$ parturients with protracted dilatation underwent normal vaginal delivery and $8.33 \%$ underwent LSCS delivery. $16.66 \%$ parturients with protracted descent underwent normal vaginal delivery, $8.33 \%$ underwent instrumental delivery and $5.55 \%$ underwent LSCS delivery.

Study done by Sanyal et al ${ }^{13}$ also reported protracted dilatation (36.5\%) to be the commonest pattern of abnormal labor. Other abnormal patterns seen were arrest of dilatation (28.1\%), protracted descent (19.8\%), arrest of descent $(11.5 \%)$ and failure of descent (4.2\%). Our results were also supported by Bottoms et al ${ }^{16}$ and Melmed et al. ${ }^{17}$ However, the study done by Godara et al ${ }^{18}$ and Shinde et al ${ }^{19}$ reported 
Table 12: Comparison ofcervimetric progress during labor with other authors

\begin{tabular}{lcccccc}
\hline $\begin{array}{l}\text { Partogram } \\
\text { group }\end{array}$ & $\begin{array}{c}\text { Philpott et al } \\
(\mathbf{1 9 7 2 )}\end{array}$ & $\begin{array}{c}\text { Lakshmidevi } \\
\text { et al (2012) }\end{array}$ & $\begin{array}{c}\text { Sanyal et al } \\
\mathbf{( 2 0 1 2 )}^{\mathbf{1 3}}\end{array}$ & $\begin{array}{c}\text { Bhuyar et al } \\
\mathbf{( 2 0 1 4 )}\end{array}$ & $\begin{array}{c}\text { Penumadu et } \\
\text { al (2014) }\end{array}$ & Present study \\
I & $78.0 \%$ & $66.5 \%$ & $80.8 \%$ & $39.3 \%$ & $67.2 \%$ & $64.0 \%$ \\
II & $11.0 \%$ & $20.0 \%$ & $15.2 \%$ & $47.9 \%$ & $22.8 \%$ & $20.0 \%$ \\
III & $11.0 \%$ & $13.5 \%$ & $4.0 \%$ & $11.67 \%$ & $10.0 \%$ & $16.0 \%$ \\
\hline
\end{tabular}

Table 13: Rate of cervical dilatation in each group by different authors

\begin{tabular}{lccccc}
$\begin{array}{l}\text { Cervical } \\
\text { dilatation rate } \\
(\mathbf{c m} / \mathbf{h r})\end{array}$ & $\begin{array}{r}\text { Philpott et al } \\
\mathbf{( 1 9 7 2 )}\end{array}$ & $\begin{array}{r}\text { Lakshmidevi et } \\
\text { al (2012) }\end{array}$ & $\begin{array}{r}\text { Bhuyar et al } \\
\mathbf{( 2 0 1 4 )}\end{array}$ & $\begin{array}{r}\text { Garg et al (2018) } \\
\mathbf{1 5}\end{array}$ & Present study \\
I & 1.68 & 1.4 & 1.41 & 1.6 & 1.4 \\
II & 0.86 & 0.8 & 0.88 & 0.76 & 0.7 \\
III & 0.18 & 0.6 & 0.59 & 0.35 & 0.53 \\
\hline
\end{tabular}

Table 14: Duration of active phase in each group by different author

\begin{tabular}{|c|c|c|c|}
\hline $\begin{array}{l}\text { Duration of active phase of } \\
\text { labor }\end{array}$ & Lakshmidevi et al (2012) ${ }^{11}$ & Bhuyar et al (2014) ${ }^{14}$ & Present study \\
\hline I & $4.1 \mathrm{hrs}$ & $4.55 \mathrm{hrs}$ & $4.3 \mathrm{hrs}$ \\
\hline II & $6.9 \mathrm{hrs}$ & $6.90 \mathrm{hrs}$ & $7.77 \mathrm{hrs}$ \\
\hline III & $9.6 \mathrm{hrs}$ & $10.16 \mathrm{hrs}$ & $11.37 \mathrm{hrs}$ \\
\hline
\end{tabular}

Table 15: Distribution of cases according to mode of delivery amongst different groups

\begin{tabular}{|c|c|c|c|c|c|c|c|c|c|c|c|c|c|c|c|}
\hline \multirow{2}{*}{$\begin{array}{l}\text { Outcome } \\
\text { of } \\
\text { labor }\end{array}$} & \multicolumn{3}{|c|}{$\begin{array}{c}\text { Philpott et al } \\
(1972)^{9}\end{array}$} & \multicolumn{3}{|c|}{ Bhuyar et al (2014) } & \multicolumn{3}{|c|}{$\begin{array}{l}\text { Lakshmidevi et al } \\
\qquad(2011)\end{array}$} & \multicolumn{3}{|c|}{$\begin{array}{l}\text { Penumadu et al } \\
\qquad(2014)\end{array}$} & \multicolumn{3}{|c|}{ Present study } \\
\hline & I & II & III & $\mathbf{I}$ & II & III & $\mathbf{I}$ & II & III & I & II & III & I & II & III \\
\hline NVD & 89.8 & 79.4 & 0.0 & 78.8 & 75.5 & 60.0 & 97.7 & 72.5 & 18.5 & 87.5 & 50.9 & 20.0 & 95.3 & 80.0 & 43.8 \\
\hline $\begin{array}{l}\text { Instru- } \\
\text { mental }\end{array}$ & 9.8 & 20.9 & 0.0 & 3.4 & 8.2 & 11.4 & 0.0 & 17.5 & 25.9 & 0.6 & 10.6 & 12.0 & 1.6 & 10.0 & 18.8 \\
\hline LSCS & 0.4 & 0.0 & 100.0 & 17.8 & 16.3 & 28.5 & 2.3 & 10.0 & 55.6 & 11.9 & 38.6 & 68.0 & 3.1 & 10.0 & 37.5 \\
\hline
\end{tabular}

higher incidence of descent abnormalities.

\subsection{Indication of instrumental delivery and LSCS $(n=16)$}

In Group I, all the parturients underwent instrumental / LSCS delivery due to fetal distress, which is not supported by the study done by Godara et al, ${ }^{18}$ who reported only $4.3 \%$ instrumental / LSCS deliveries due to fetal distress. Lakshmidevi et al $^{11}$ also reported that $100 \%$ of the parturients of Group I and II underwent instrumental / LSCS delivery due to fetal distress.

In Group II, 25\% each parturients underwent instrumental / LSCS delivery due to fetal distress, arrest of descent, protracted descent and protracted dilatation respectively. In Group III, $22.2 \%$ parturients each underwent instrumental / LSCS delivery due to fetal distress, arrest of descent and protracted descent respectively. Godara et al ${ }^{18}$ reported fetal distress $(13.75 \%)$, protracted dilatation $(17.5 \%)$, arrest of descent $(50 \%)$ and arrest of dilatation (18.75\%) to be causes for instrumental / LSCS deliveries in parturients with abnormal partograph. Lakshmidevi et al ${ }^{11}$ in their study reported that fetal distress in $40.9 \%$, secondary arrest of descent in $50 \%$ and secondary arrest of dilatation in $9.1 \%$ of Group III parturients were the reasons for instrumental / LSCS deliveries.

\subsection{APGAR score}

Apgar score of $>7$ was seen in $98.4 \%$ newborns of Group I, $85 \%$ of Group II and $62.5 \%$ of Group III newborns, while $15 \%$ of Group II and $37.5 \%$ of Group III newborns had an apgar score $<7$. Majority of the newborns of all the three groups are having apgar score $>7$. The association between apgar score and groups was found to be statistically significant $(\mathrm{p}=0.002)$. Godara et al ${ }^{18}$ showed $94 \%$ newborns with normal partogram had apgar score $>7$ and $73.8 \%$ newborns with abnormal partogram had apgar score $>7$ at 1 minute, which is quite comparable with our study results.

\subsection{Maternal morbidity}

In the present study, urinary tract infection was seen in 1 parturient each of Group I and II and 2 parturients of Group III had urinary tract infection. Fever and wound infection was seen in 2 parturients each of Group II and III respectively. Maternal mortality was not seen in our 
study. Sanyal et al ${ }^{11}$ reported fever in $1 \%$ parturients with normal labor and $6.2 \%$ parturients with abnormal labor. $12.5 \%$ wound complications were seen in abnormal labor, while they reported it to be $2 \%$ in parturients with normal labor. The results are quite similar to our study results.

\subsection{Duration of hospital stay}

The mean duration of hospital stay was highest in Group III, followed by Group II and lowest in Group I.

\section{Conclusion}

The modified partogram in use developed by WHO is the most widely used for assessment of progress of labor. It helps in accurate assessment of fetal condition with the progress of labor, gives information when an intervention needs to be applied and when the parturient needs to be taken for instrumental / LSCS delivery. Being very simple, cost effective and easy to interpret, it is highly recommended throughout the institutions, especially in resource deficient settings. In the present study, when the partogram remained to the left of alert line (normal), majority of the parturients underwent normal vaginal delivery, while in parturients with partogram between the alert and action lines (abnormal) and where partogram crossed the action line (abnormal), high incidence of instrumental / LSCS deliveries were seen. Majority of the newborns had apgar score $>7$ with no maternal or fetal mortality. These patterns helped the obstetrician take immediate and appropriate decision regarding going ahead with normal labor or to go for instrumental / LSCS deliveries.

Thus, partogram has helped in identification of abnormal labor patterns early during the labor progress; helped in prediction of mode of delivery, need for augmentation of labor with prediction of maternal and perinatal outcome.

The MDG can be achieved by reutilizing the partogram. The only disadvantage being that it requires continuous monitoring but at the same time it gives satisfaction to a woman in labor as she is monitored by the same doctor there by decreasing her anxiety.

\section{Source of Funding}

None.

\section{Conflict of Interest}

None.

\section{References}

1. Mishra R. Management of labour. In: Mishra R, editor. Practical Obstetric Problems. UK: Ian Donald; 2007. p. 506-21.

2. Penumadu K, Hariharan C. Role of partogram in the management of spontaneous labour in primigravida and multigravida. Int $J$ Repord Contracept Obstet Gynecol. 2014;3(4):1043-9.

3. Javed I, Bhutta S, Shoaib T. Role of partogram in preventing prolonged labour. J Pak Med Assoc. 2007;57(8):408-11.

4. Neilson JP, Lavender T, Quenby S, Wray S. Obstructed labour. $B r$ Med Bull. 2003;67(1):191-204.

5. Tayade S, Jadhao P. The impact of use of modified who partograph on maternal and perinatal outcome. Int J Biomed Adv Res. 2012;3(4):256-62.

6. Manjulata VR, Anitha GS, Shivalingaiah N. Partogram: Clinical study to assess the role of partogram in primigravida in labor. Int J Report Contracept Obstet Gynecol. 2016;5(4):1014-25.

7. Partogram; 2019. Available from: https://web.archive.org/web/ 20110927221515/http://staff.um.edu.mt/csav1/lectures/partogram. pdf.Accessedin.

8. Friedman EA. Evolution of graphic analysis of labor. Am J Obstet Gynecol. 1978;132(7):824-7.

9. Philpott RH. Graphic records in labour. BMJ. 1972;4(5833):163-5.

10. World Health Organization. The partograph. A Managerial tool for the prevention of prolonged labour. In: WHO, eds. Section 1: The Principle and Strategy. WHO Document Number: WHO/MCH/88.3. Geneva: WHO.

11. Lakshmidevi M, Malini KV, Shetty VH. Partographic Analysis of Spontaneous Labour at Term in Primigravida. J Obstet Gynaecol India. 2012;62(6):635-40.

12. Dangal G. Preventing prolonged labor by using partograph. Internet Journal of Gynecology \& Obstetrics. 2008;8(2):1-1.

13. Sanyal U, Goswami S, Mukhopadhyay P. The Role of Partograph in the Outcome of Spontaneous Labor. Nepal J Obstet Gynaecol. 2014;9(1):52-7.

14. Bhuyar S, Deshmukh P. Partographic study of progress of labour in primigravida. Int $J$ Reprod, Contracept, Obstet Gynecol. 2014;3(1):109-12.

15. Garg P, Shivhare N. Influence of partograph tracing in management of labour in primigravida. J Med Sci Clin Res. 2018;06(05):730-6.

16. Bottoms SF, Hirsch VJ, Sokol RJ. Medical management of arrest disorders of labor: A current overview. Am J Obstet Gynecol. 1987;156(4):935-9.

17. Melmed H, Evans M. Predictive value of cervical dilatation rates. I. Primipara labor. Obstet Gynecol. 1976;47(5):511-5.

18. Godara J, Kang A. The study of course of labor using modified WHO partograph. Sch J App Med Sci. 2018;6(6):2450-7.

19. Shinde KK, Bangal VB, Singh RB. The study of course of labor by modified WHO partograph. Int J Biomed Adv Res. 2012;03(05):391-

\section{Author biography}

Deepika Verma Professor

Surabhi Gupta Post Graduate Student

Cite this article: Verma D, Gupta S. A clinical study on the utility of alert and action line on partogram in management of labor in primigravidae and its impact. Indian J Obstet Gynecol Res 2020;7(3):379-386. 